\section{WESTMINSTER MEDICAL SOCIETY.}

Saturday, Feb. 26, 1842.

Dr. Golding Bird, President.

ADMINISTRATION AND EFFECTS OF LEAD UPON THE SYSTEM.-MEDICAL KNOWLEDGE IN CHINA.

The President wished to know the experience of members relative to the effects of the acctate of lead. He had been in the habit of giving it in cases of hæmoptysis, in doses of two grains every four hours, and had never witnessed any ill effects from its exhibition. He spoke from the experience of many years, and he had been much surprised, therefore, at the simultaneous occurrence of three recent cases, in which symptoms of colic had been manifested. He was very desirous of ascertaining from members, whether he was to consider these thrce cases as the rule or the exception. In one of these, hæmoptysis was complicated with tuberculous consumption, the hamorrhage was stopped in four hours, and on the next day symptoms of colic manifested themselves; the next case was one of menorrhagia; and in the third case, which was one of endocarditis, three grains of the acetate of lead were given every four hours, and in two days afterwards colic supervened.

Mr. Elliot could bear similar testimony to the value of acetate of lead, as a remedial agent; he had been long in the habit of administering it in large doses. In seaport towns it was very common for sailors and naval officers to suffer from chronic hamoptysis, and the medium dose in which he had wituessed its exhibition in these cases, was three grains every three hours, with one drachm of acetic acid prepared from the pyroligneous acid. The bowels were kept open during the period of administering the remedy, and no vegetables were allowed, as these were liable, in combination with the acids of the stomach, to form and disengage carbonic acid gas, according to the statement of Dr. A. T. Thompson, who was in the habit of administering this remedy very frequently, at University College Hospital. He (Mr. Elliott) could not recal a single case in which any evil effects followed the administration of the acetate of lead. There were some physicians who disapproved of its employment.

Dr. LANkester inquired if Dr. Bird had noticed the appearance of Dr. Burton's test of the presence of lead in the system-viz, a blue line running along the cdge of the gums nearcst to the teeth, in those cases in which he had exhibited that medicine.

The President observed that he considered this test of Dr. Burton to be as true a one of the action of lead upon the system, as a redness and swelling of the gums was a test of the presence of mercury. He had noticed the peculiar appearance alluded to by the last speaker, in some patients in the Charing Cross and Guy's Hospitals.

Mr. SNow observed that, in his practice, he had never seen any ill effects to arise from the acetate of lead. In one case of hæmatemesis in which it was administered, symptoms of colic came on, and there was the blue line along the gums; there was great debility present in this case, which he attributed to the lead, although he did not know what the dose had been; he did not approve of large doses of lead being given to persons of weakened constitution.

Mr. Chowne related a case in which one ounce of acetate of lead had been given by mistake instead of a similar dose of sulphate of magnesia. Severe vomiting fortunately ensued, which was kept up by such appropriate remedies as a naval surgeon's cabin could command. 'The person recovered without the supervention of any bad effects beyond the debility caused by long continued vomiting.

The President observed that he had been so long in the habit of giving lead with impunity, that he should almost have doubted the fact of its being a poison, had he not met with two cases of children who had been poisoned by it; one of these children had a bruised knee, to which some Goulard water had been applied, and the bottle containing it being labelled as "mushroom ketchup," the two children very soon finished it between them.

A Menber observed that he was a stranger to the ill effects arising from the administration of lead internally; he did not consider that the blue line along the gums could always be relied upon as a sure diagnostic. There was a patient in the University College Hospital, who had not taken one grain of lead, but had taken large and frequent doses of mercury, yet he had the blue line along the gums; in one case, where the same symptoms showed itself, the patient had been taking the oxide of zinc and the nitrate of silver, and he had generally found that whenever any metallic oxides had been taken the blue line along the gums was to be seen; lead might be taken in such quantities as to induce paralysis, and yet no blue line be present along the gums.

The President remarked that in catarrhal stomatitis, and in affections of the mouth, or where the constitution is in a bad and unhealthy state, and there was much livor and pallor of the gums, it might be difficult, perhaps, to distinguish such a state from one produced by mercury; but in the absence of these symptoms, and where lead had been taken, the blue line along the gums was to be considered as a sure symptom of the presence of that remedial agent in the system. In the peculiar affection denominated the "hand drop," and which is frequently met with in painters where the extensor muscles of the arm are paralysed, this, being frequently caused by the imbibition of lead into the system, is as frequently accompanied by the blue line along the margin of the gums. These facts induced him to place great reliance upon this diagnostic test of lead in the system.

Mr. Streeter observed that, during the prevalence of the cholera, he had been in the habit of treating the carly symptoms of diarrhœa which preceded the cholera with one grain doses of the acetate of lead, in combination with opium and capsicum ; this was given after each liquid dejection from the bowels, yet he had never met with any bad effect from the lead thus exhibited. He recollected a case in which one ounce of the acetate of lead had been taken; all emetics failed to rouse the dormant torpor until mustard was tried, and that succeeded in dislodging the poison.

The President observed, in allusion to the cases of poisoning, by Goulard water, which he had mentioned, that, on examining the bodies after death, the intestinal canal was found to be contracted along its entire course, to the diameter of an earth-worm.

Mr. Downing was now called upon to read his paper on

THE STATE OF MEDICINE AND MEDICAL KNOWLEDGE ANONG THE CHINESE.

The antiquity of the Chinese nation was very great, and their discoveries of the principles subservient to the preservation of life was dated back to a very distant period of time. The earliest medical knowledge they possessed was of the substances of the mineral kingdom. Their general ideas of medical knowledge possessed great affinity with that of the western nations of Europe. They traced their reception of medical science to one whom in their figurative language they termed the Divine Husband; he it was who taught them the use of herbs in the treatment of disease; and the remedies which he prescribed are still considered by the Chinese as among the most excellent of the art, and it is to this blind and fancied superstition, still prevalent among them, that the author was induced to ascribe the low state of medical science among this strange and singular people. Their present knowlgdge of the healing art was the same as it 
had been for many years past ; they had made no recent progress or improvement. Their peculiarity of practice might be estimated from the fact, that, in treating the sick, if the patient recovered it was all well, but if he died, it was the result of chance, and therefore chance alone bore the blame. If, in treating a disease, the Chinese doctor struck out into a new plan, the patient and his friends generally gave up their case as a lost one. The native practitioners in China read but few books; their fees were very small, unless in the case of those who had obtained a high reputation, when the amount of their fees was raised in proportion to their skill. Quacks and charlatans abounded throughout every town and village in China. In the capital there is an examining board, but which is only for the purpose of superintending those who attend the government and the emperor. In investigating and treating a disease, the physician attends once only, but does not continue to attend during the progress of the disease. In treating the venereal disease, it is left only to the care and attention of quacks and nostrum venders, as the regular Chinese practitioners will not attend upon patients suffering this discase. Their medical books are full of jargon, and their nosological opinions of disease are truly magical. They consider the human body to be composed of certain elemental substances, and when these are interfered with, disease is immediately set up. Little is known of anatomy, as dissection is not allowed; they sometimes preserve the bones of their relatives after death, and by that means some slight knowledge of osteology is kept up among them. They consider the heart to be on the right side of the body, and the liver on the left. They were acquainted with some of the doctrines of the circulating system as far back as their earliest historic records go, upwards of 2,000 years since; they are not, however, in the present day cognizant of any circumstances connected with the function of respiration. Their plysicians recognise twenty-four kinds of pulse, which they say belong to different parts of the body; the pulse of the heart and liver are on the right side, and from the pulse they profess to be able to detect childbirth Their facility in detecting the different varicties of the pulse is extraordinary, and far surpasses the skill of more civilised nations, and from it they profess to be able to detect the duration of disease.

They consider that the nose is the first part of the body formed in embryo. 'Their pathology is divided into infinite varieties, and is obscured by great wordiness both of detail and description. Their materia medica is a most absurd one; their vegetable which enjoys the highest reputation as a curative agent is called "geasing." 'Tea, tobacco, and Malay camphor have great virtues attributed to them. Consumption, which is a very prevalent disease in China, is treated with foxes' bones and otter's horns ; a dose of tiger' bones invests a person with courage, and elephant's cyes, boiled, are considered as a good remedy for inllamed eyes. Mercury is used in the venereal disease; calomel and corrosive sublimate are the most commonly used preparations of this mineral. Cinnabar is very much used in chemistry, but it is prepared in a very uncertain and incorrect manner; but the use of mercury is much less prevalent in the treatment of disease than it formerly was. They consult the stars and the native astrologers. Their principal works on medicine are four in number, each comprising many volumes, and they abound in fortunate days, sound and unsound theories are mingled together, and these were exemplified by many ex tracts from Chinese works on medicine. Hernia has been mistaken for the vapours, yet their natural sagacity is prominently displayed in some cases, even where European practitioners have failed, the native practitioners have succeeded in effecting a cure; but the reverse, it need hardly be observed, is the most commonly met with. There are hospitals open at Macao and Canton; they employ the moxa, which originally came from China; acupuncture, too, is one of their remedies, and, in employing it, they use silver needles; they innoculate by introducing dossils of lint dipped in small-pox matter, into the nose. Mr. Pearson originally proposed vaccination in China among the Chinese, and it is now frequently performed. The inferior practitioners, like those of a similar class in England, placard their houses and walls with their nostrum bills. The native physicians prescribe many drugs, either in the form of decoction or bolus, which latter is sometimes so large, that the patient is sometimes nearly choked, and may die; and should such an event occur, it is considered as of little consequence as the result of fate.

Dr. Golding Bind remarked that, however odd and singular some of their theories might be, yet that the observations of the Chinese were not more strange respecting the pulse than those which had been supported by Dr. Rowe, a member of the College of Physicians.

After some remarks from Mr. Streeter,

Mr. Elliotr said that he was desirous of knowing if the ox-gall was used by the Chinese, as it was now employed by many London physicians; its bitter principle being supposed valuable in deranged states of the liver and gall bladder.

The Presinent observed that-though Dr. Copland, Dr. Johnson, and other London physicians prescribed the ox-gall, in combination with salts of iron and purgatives, in cases of indigestion and inspissated bile-it was absurd to suppose that they prescribed it on the principle of one bitter product providing for the due and healthy discharge of a bitter secretion.

Mr. Downing stated that he believed the Chinese used the-ox gall, as they used the gall of all other animals.

Mr. Brooke was desirous of knowing if the Chinese were acquainted with surgery, or with the performance of any surgical operations, or whether they had any knowledge of calculous complaints.

Mr. DownING replied that they knew nothing of surgery, and were very averse to the use of the knife ; they had a great horror of the lancet, and consequently never bled; there was no instance, he believed, on record, of their performing any capital operation; he had known cases brought to the lospitals of Macao and Canton of broken limbs of seven or eight years' standing, and which required amputation. He believed there were some specimens of the pathology of diseases in China in the museum of Guy's Hospital.

Some desultory conversation, bearing upon the connection between the ancient traces of medical knowledge in Egypt and China, succeeded, but we do not report any portion of it, as no remarks of a practical nature were made by any of the members present.

\section{ACADEMY OF SCIENCES, PARIS.} February, 21.

ANEURISM OF THE HEART.

M. Larrey read a memoir on aneurism of the heart. In a former paper the author had endeavoured to prove that this disease is not incurable, if treated before it has arrived at the last period. 'The means employed by M. Larrey are, the application of cupping glasses over the left hypochondrium and back, followed by moxas ; general bleeding, the use of ice, especially at the commencement, and antispasmodics. The moxa, according to M. Larrey, possesses an exciting property, the effects of which extend to the heart, and tend to restore the weakened parietes of the heart to their natural condition. The application of ice, curiously enough, acts in the same way. M. Larrey presented the cases of four women, treated by him on the above mentioned principles. In one case, fiftynine moxæ and one hundred applications of the cupping glass had been resorted to. 